\title{
Impact of promotion of mango and liver as sources of vitamin A for young children: a pilot study in Burkina Faso
}

\author{
CP Nana ${ }^{1}$, ID Brouwer ${ }^{2, *}$, NM Zagré ${ }^{3}$, FJ Kok ${ }^{2}$ and AS Traoré \\ ${ }^{1}$ Centre de Recherche en Sciences Biologiques, Alimentaires et Nutritionnelles (CRSBAN), Université de \\ Ouagadougou 03, BP7021 Ouagadougou 03, Burkina Faso: ${ }^{2}$ Division of Human Nutrition, Wageningen \\ University, PO Box 8129, 6700 EV Wageningen, The Netherlands: ${ }^{3}$ Helen Keller International, \\ Représentation au Niger, BP 11728 Niamey, Niger
}

Submitted 9 June 2005: Accepted 21 November 2005

\begin{abstract}
Objective: To assess the effectiveness of a behaviour change approach, with or without financial support, in improving vitamin A (VA) intake and serum retinol concentration through mango and liver consumption by children.

Design: A parallel design (no control area) was used to assess changes in VA intake and serum retinol over a 15 -week period.

Setting and subjects: A pilot study was implemented in the Department of Kokologho, a rural area in central west Burkina Faso. One hundred and fifty children aged 2-3 years were randomly selected and assigned to two treatment groups: PA\$\$ (promotional activities and financial support) and PA (promotional activities).

Results: The intervention significantly increased $(P<0.001)$ total VA intake by $56 \%$ in PA\$\$ and by $50 \%$ in PA. VA intake from liver increased significantly $(P<0.001)$ from $12.7 \pm 23.5$ to $155.3 \pm 56.3 \mu \mathrm{g}$ retinol activity equivalents (RAE) in PA $\$ \$$ and from $21.6 \pm 29.7$ to $135.3 \pm 44.9 \mu \mathrm{g}$ RAE in PA. Changes in VA intake from liver were significantly higher $(P=0.004)$ in PA $\$ \$$ compared with PA. Mean serum retinol concentration increased significantly by $26 \%(P<0.001)$ in PA\$\$ and $30 \%(P<0.001)$ in PA. Changes in serum retinol concentration $\left(0.13 \mu \mathrm{mol} \mathrm{l}^{-1}\right.$ in $\mathrm{PA} \$ \$$ vs. $0.17 \mu \mathrm{moll}^{-1}$ and in PA) did not differ significantly $(P=0.455)$ between groups over the intervention.

Conclusion: Promotional activities on mango and liver intake effectively increased VA intake and serum retinol concentrations. Although an additional beneficial effect of financial support on liver intake was observed, this did not translate into a further increase in serum retinol concentration.
\end{abstract}

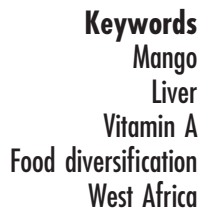

Vitamin A (VA) deficiency is still a severe public health problem in Burkina Faso (BF) ${ }^{1}$ despite the biannual mass campaign distributing high-dose VA capsules to children under 5 years of age. Therefore, there is an urgent need to develop effective interventions based on better use of local food sources rich in VA (e.g. provitamin A carotenoid or retinol) to complement the ongoing supplementation programmes in a sustainable way. Although the effectiveness of plant provitamin A carotenoids in combating VA deficiency has been questioned ${ }^{2,3}$ and current evidence shows that the bioefficacy of provitamin A carotenoids is lower than previously thought ${ }^{4-6}$, randomised trials showed that consumption of red palm oil, mangoes or dark-green leafy vegetables, with or without fat added or deworming, was effective in improving VA status ${ }^{7-11}$.

In developing countries, provitamin A carotenoids are the main source of VA in the diet, but for various reasons the frequency and amount consumed by children are not adequate $^{12}$.

A previous food ethnographic study conducted in Kokologho in central west BF identified mango and liver as key foods to be included in a food-based intervention, and lack of financial means was indicated as a major limiting factor to liver consumption ${ }^{13}$. The rationale behind the present study was to investigate the effectiveness of promoting the consumption of mango and liver in improving VA intake and serum retinol of children in freeliving conditions. The objectives of the study were: (1) to assess the effect of promotional activities on mango and liver intake; (2) to assess if this increased intake of liver and mango led to an increased serum retinol concentration; and (3) to assess the additional effect of providing financial support on the changes in VA intake and serum retinol concentration. 


\section{Methodology}

\section{Study design}

The study had a parallel design with two treatment groups, with measurements at baseline and at the end of a 15 -week period. The intervention consisted of a behaviour change approach using promotional activities, including weekly home visits, to inform on health benefits and negotiate and motivate parents to provide one piece of liver (about $10 \mathrm{~g}$ ) on a weekly basis and two fresh mangoes (about $150 \mathrm{~g}$ ) daily to their children. One group received additional financial support (PA\$ $\$$, promotional activities plus financial support) while the second group (PA, promotional activities) did not. The consumption of mangoes and liver was monitored weekly over a 15-week period.

\section{Study area and subjects}

The study was conducted in the Department of Kokologho located in rural central west BF. A household census was conducted at the beginning of the study. Households without children 2-3 years old were excluded; a sample of $150^{*}$ children was randomly selected ${ }^{14}$ and randomly assigned to the PA\$\$ or PA group. Written informed consent was obtained from parents prior to children's enrolment. The protocol was approved by the Ethical Committee for Health Research of Burkina Faso. At baseline all subjects received $600 \mathrm{mg}$ anthelmintic drug (mebendazole, dry powder for suspension; SmithKline Beecham Pharmaceuticals, Brentford, UK) in order to reduce parasite load. The last VA supplementation in the study area took place four months before the start of the intervention.

\section{Variables and measurement methods}

\section{VA intake}

Throughout the study, consumption of mango and liver was reported through weekly recall. VA intake was estimated using a semi-quantitative food-frequency questionnaire (FFQ). The method was validated in Niger (Delisle et al., unpublished dataf), where the population has a comparable cereal-based diet with low intake of animal VA sources. Usual household measures and prices were used to estimate the portion size. The amount of retinol and provitamin A-rich foods consumed by the child was converted into VA intake using food composition

\footnotetext{
*A sample size of 62 was estimated per group (and extended to 75 to take into account possible dropouts) based on an $\alpha$ error of 0.05 , a statistical power of 0.85 and an expected reduction of one-quarter (from $85 \%$ to $63.8 \%$, based on Zagré et al..$^{7}$ ) in the proportion of children with serum retinol concentration $<0.7 \mu \mathrm{moll}^{-1}$ between baseline and the end of the intervention.

tDelisle H, Bakari S, Ferland G. Validation study on a simplified dietary method for the assessment of vitamin A deficiency risk in Niger. Report to OMNI-Research, Washington, DC, 1997, 70 pp.
}

tables ${ }^{15,16}$. The Institute of Medicine-recommended conversion factors ${ }^{17}$ from provitamin A to retinol activity equivalent (RAE) were used*. Total daily VA intake was compared with the Food and Agriculture Organization/ World Health Organization safe intake level ${ }^{18}$. Inadequate VA intake was defined as intake below $62.5 \%$ of the safe level of intake ${ }^{19}$.

\section{Serum retinol concentration}

At baseline and the end of the intervention, venous blood was taken between 07.00 and 09.00 hours, on two consecutive days, from fasted children using a needle fitted to a $5 \mathrm{ml}$ non-heparinised tube. Blood was protected from light, placed on ice and transported immediately to the laboratory. Blood samples were then centrifuged at $1000 \mathrm{~g}$ for $10 \mathrm{~min}$ at $4^{\circ} \mathrm{C}$; serum was separated into aliquots, the tubes wrapped in aluminium foil to protect the contents from light and stored at $-18^{\circ} \mathrm{C}$ until analysis at the end of the intervention. Serum retinol concentration was measured in duplicate, using high-performance liquid chromatography ${ }^{20}$, at the laboratory of the 'Unite de Formation et de Recherche en Sciences de la Santé' in BF. The standard cut-off point of $0.70 \mu \mathrm{moll}^{-1}$ was used for low serum retinol ${ }^{21}$.

\section{Anthropometric measurements and morbidity}

Child age was determined based on the birth certificate or health record; in the absence of these, a calendar of local events was used to determine the birth date of the child as accurately as possible. Height $(\mathrm{cm})$ and weight $(\mathrm{kg})$ were measured following standardised methods ${ }^{22}$. The occurrence of illness in the previous 15 days was assessed through maternal recall, using a validated $\operatorname{method}^{23}$.

\section{Socio-economic variables}

At baseline, data were collected on marital status, household size, parents' education level, secondary occupation of the parents besides farming, number of siblings of the target child, the presence of a mango tree and husbandry activity.

\section{Data processing}

Fourteen out of the 150 children did not have a complete dataset and were excluded from further analysis. Differences between groups for socio-economic and anthropometric variables without normal distribution were tested using the Mann-Whitney $U$-test for continuous variables and the chi-square test for categorical variables. The McNemar test was used to compare changes in the prevalence of low serum

\footnotetext{
$* 1 \mu \mathrm{g}$ RAE $=1 \mu \mathrm{g}$ retinol or $12 \mu \mathrm{g} \beta$-carotene in a mixed diet or $24 \mu \mathrm{g}$
} of other provitamin A carotene in a mixed diet. 
retinol and inadequate intake of VA within groups for categorical variables. Changes in mean VA intake and mean serum retinol concentration within each group were tested by the paired $t$-test or the Wilcoxon signedrank test depending on whether the variable was normally distributed. Differences between PA\$\$ and PA in changes in VA intake and serum retinol concentration were examined by the independent samples $t$-test or the Mann-Whitney $U$-test according to whether or not variables were normally distributed. Multiple linear regression analysis was used to assess the effect of treatment group on pre-post intervention changes in serum retinol concentration, controlling for baseline serum retinol concentration, VA intake, health and anthropometric variables, and socio-economic variables. For all tests a $P$-value below 0.05 was considered significant. All analyses were conducted using SPSS version 11.0 for Windows (SPSS Inc., Chicago, IL, USA) ${ }^{24}$.

\section{Results}

Table 1 shows the characteristics of the subjects and their households at baseline. The small husbandry activities included rearing of chickens, guinea fowl, goats, sheep and pigs. There were no significant differences between the two groups, although PA appeared to be worse off according to the nutrition and morbidity indicators at baseline. Nutrition and morbidity indicators did not differ significantly after the intervention (data not shown) except for fever in PA, which reduced from $20.3 \%$ at baseline to $6.0 \%$ after the intervention.

Table 1 Socio-economic and individual characteristics of the study population at baseline

\begin{tabular}{lcc}
\hline & $\begin{array}{c}\text { PA\$\$ } \\
(n=67)\end{array}$ & $\begin{array}{c}\text { PA } \\
(n=69)\end{array}$ \\
\hline $\begin{array}{l}\text { Household characteristics } \\
\text { Average number of pre-school }\end{array}$ & $1.0 \pm 0.6$ & $1.0 \pm 0.5$ \\
children, mean \pm SD & & \\
Total number of siblings of & $4 \pm 2$ & $3.0 \pm 1.9$ \\
target child, mean \pm SD & & \\
Household size, mean \pm SD & $15.0 \pm 7.6$ & $14.0 \pm 9.9$ \\
Marital status (\%) & 100 & 100 \\
Polygamy (\%) & 58.2 & 47.8 \\
Animal husbandry activity (\%) & 89.6 & 92.6 \\
Household with mango tree (\%) & 83.6 & 79.7 \\
Individual characteristics & & \\
Age (months), mean \pm SD & $29 \pm 5$ & $30 \pm 6$ \\
Sex (\% boys) & 46.3 & 52.2 \\
HAZ, mean \pm SD & $1.5 \pm 1.0$ & $-1.7 \pm 1.1$ \\
Stunted (\% with HAZ <-2.0) & 28.4 & 37.7 \\
Illness (\%) & 25.4 & 34.8 \\
Diarrhoea* (\%) & 13.4 & 17.4 \\
Cough* (\%) & 4.5 & 11.6 \\
Fever* (\%) & 13.4 & 20.3 \\
\hline
\end{tabular}

PA\$\$ - promotional activities and financial support; PA - promotional activities; SD - standard deviation; HAZ - height-for-age Z-score.

* Morbidity during the two weeks prior to the beginning of the study.
Table 2 shows that, throughout the intervention, the average daily consumption of ripe mangoes in both groups was significantly lower $(P<0.05)$ compared with baseline while that of liver increased significantly in both groups $(P<0.001)$. The total daily VA intake at baseline was comparable in both groups $(273 \pm 108 \mu \mathrm{g}$ RAE in PA $\$$ \$ and $272 \pm 115 \mu \mathrm{g}$ RAE in PA, $P=0.45)$ and increased significantly at the end of the intervention $(P<0.001)$ to a safe level in both groups. The proportion of children at risk of inadequate VA intake decreased from about $45 \%$ to less than $5 \%$ in both groups $(P<0.001)$. By the end of the intervention, the contribution of mangoes to total VA intake decreased significantly $(P<0.05)$ from $86.5 \%$ to $44.0 \%$ in PA $\$$ and from $84.0 \%$ to $47.0 \%$ in PA, while that of liver increased significantly $(P<0.001)$ from $4.5 \%$ to $37.0 \%$ and from $7.0 \%$ to $34.0 \%$, respectively (Table 2 ). Due to limited availability of hare, guinea fowl and chicken liver at the market, the liver consumed came mainly from goat. Increase in VA intake from liver was significantly higher $(P<0.05)$ in $\mathrm{PA} \$ \$$ than in $\mathrm{PA}$, while that from mangoes was not significantly different $(P=0.29)$. Mean serum retinol concentration increased significantly from 0.81 to $0.94 \mu \mathrm{moll}^{-1}(P<0.001)$ in $\mathrm{PA} \$ \$$ and from 0.82 to $0.99 \mu \mathrm{moll}^{-1}(P<0.001)$ in PA. Change in serum retinol concentration $\left(0.13 \mu \mathrm{moll}^{-1}\right.$ vs. $0.17 \mu \mathrm{moll}^{-1}$ for PA $\$$ vs. PA) over the intervention did not differ significantly between groups $(P=0.455)$. At baseline, the proportion of children with serum retinol concentration $<0.7 \mu \mathrm{mol}^{-1}$ was $32.8 \%$ in PA $\$$ and $36.2 \%$ in PA, decreasing to $19.4 \%$ and $14.5 \%$, respectively $(P<0.05)$, after the intervention.

Table 3 shows that treatment group was not a significant determinant $(P=0.45)$ of pre-post intervention changes in serum retinol concentration among the children, suggesting that the financial support did not offer an extra benefit. A higher serum retinol concentration before the intervention $(P=0.000)$ and a larger household size $(P=0.001)$ were associated with a lower increase in serum retinol concentration during the intervention.

\section{Discussion}

The present study investigated the effectiveness of promotional activities aimed at increasing liver and mango consumption to improve vitamin A intake and serum retinol concentration of children under free-living conditions. Overall, the results indicate that both VA intake and serum retinol concentration improved significantly between baseline and the end of the intervention. In the absence of a true control group, it is difficult to fully attribute this improvement to the intervention. Finding a non-intervention community that is sufficiently comparable can be difficult ${ }^{25}$ and the cross-over effect in free-living conditions could not be ruled out. However, the results of a previous food consumption study carried out a year before the current intervention, in the same area during the same period 
among children of the same age group, indicated an intake of VA four times lower in a non-intervention situation $^{13}$. Assuming a negligible year-to-year variation in VA intake, the improvement in VA intake and serum retinol concentration may be attributed to the effect of promotional activities.

The magnitude of the increase in serum retinol concentration for an average intake of VA (0.13 to $0.17 \mu \mathrm{moll}^{-1}$ change for about $400 \mu \mathrm{g}$ RAE per day) was greater in our study than reported in previous studies $^{5,7,9,10}$ where VA intake was much higher. This might be explained by the use of different methods to measure VA intake, as the extent of measurement error varies with the method used $^{26}$. However, a more plausible explanation may be the difference in the source of VA intake. In our study, a combination of animal and plant sources was used while the other studies used exclusively plant sources. As liver is the richest source of retinol ${ }^{27}$, with a bioavailability of more than $80 \%^{28}$, weekly consumption of a piece of liver (about $10-11 \mathrm{~g}$ ) as recommended in the intervention might have contributed to the greater improvement in serum retinol concentration of our children. A recent study on the effectiveness of daily supplementation with vitamin A-rich foods or capsules in improving serum retinol concentration in night-blind pregnant women indicated that the increase of serum retinol concentration in women consuming goat liver was higher than in those receiving the same amount of VA through a low-dose VA capsule, amaranth greens or carrots $^{29}$. In our study, it is probable that the improved intakes of protein, iron and zinc through the consumption of liver, and the deworming prior to the intervention, enhanced the effect on serum retinol, as also reported by previous studies $9,10,11,29,30$.

Our results indicating that changes in serum retinol concentration were significantly influenced by baseline serum retinol were consistent with results from other studies $^{7,9,31}$. Household size was the second predictor of serum retinol concentration changes. Kjolhede et al. ${ }^{32}$ reported similar results from Java; an obvious explanation, according to the authors, would be that the more people have to be fed in the family, the less VA per person is available. PA\$ showed a relatively lower contribution from mangoes and a higher contribution from liver to total VA intake compared with PA. Most probably because of the financial support, PA $\$$ focused more on liver consumption than on mangoes. However, the higher intake of VA in PA\$ did not translate into further increased serum retinol concentration likely because of the limitation of serum retinol concentration as indicator of VA status ${ }^{21}$ in the presence of confounders such as infections, malnutrition or organ diseases $^{33}$. To reduce the potential effect of infections, an antihelmintic drug was given at the beginning of the intervention. 
Table 3 Potential predictors of changes in serum retinol of children

\begin{tabular}{lccccc}
\hline & & \multicolumn{4}{c}{ Multiple linear regression* } \\
\cline { 3 - 6 } & $R^{2} \dagger$ & $\begin{array}{c}\text { Regression } \\
\text { coefficient }\end{array}$ & $\begin{array}{c}\text { Standard } \\
\text { error }\end{array}$ & $\begin{array}{c}95 \% \text { confidence } \\
\text { interval }\end{array}$ & $P$-value \\
\hline Treatment group $(\mathrm{PA}=0)$ & 0.004 & +0.04 & 0.054 & $(-0.660,+0.147)$ & 0.455 \\
Retinol pre intervention & 0.178 & -0.485 & 0.090 & $(-0.663,-0.307)$ & 0.000 \\
Household size & 0.139 & -0.009 & 0.003 & $(-0.014,-0,004)$ & 0.001 \\
\hline
\end{tabular}

PA - promotional activities.

${ }^{*}$ Corrected for education of father and mother, secondary occupation of father and mother, polygamy and household size, the only variable with significant effect.

†Percentage of variance explained by the variable.

Our study showed that financial support has an additional effect to that of promotional activities because VA intake from liver was significantly higher in PA\$\$. However, financial means did not seem to be the major constraint on not consuming liver in the amount proposed, as subjects in PA showed a substantial increase in VA intake from liver too.

In the developing world, multiple micronutrient deficiencies generally coexist ${ }^{34,35}$ and combined supplementation becomes an appealing strategy, although controlled studies have indicated a likely competition in absorption of iron and zinc ${ }^{36,37}$ and the possible adverse effect of iron supplementation on VA status ${ }^{38}$. Liver may be a key food to address VA and iron deficiencies simultaneously in BF in combination with mangoes, and therefore both could be targeted at national level as foods of interest in developing effective dietary interventions. The promotion of liver and mangoes consumption is likely to be effective in preventing VA deficiency (maintaining VA status), but not in correcting existing VA deficiency. Therefore, it should be complemented with additional approaches to increase VA intake, as well as by public health measures such as deworming programmes, in order to strengthen their effectiveness in controlling VA deficiency.

\section{Conclusion}

Our study indicated that promotional activities were feasible in a rural area, resulting in increased VA intake and serum retinol concentration of children. Financial support additionally increased the consumption of liver compared with promotional activities, but this did not result in a further increase of serum retinol concentration.

The amount of liver proposed in this intervention seems to be affordable to the population in the rural area, suggesting that it is possible to increase the consumption of liver if effective promotional activities are used. Therefore, liver combined with mangoes appears to be suitable to reduce VA deficiency in BF, but may not be sufficient, and needs to be complemented by other public health measures.

\section{References}

1 Ministère de la Santé. Plan National d'Action pour la Nutrition, version révisée. Ouagadougou: Ministère de la Santé, 2001.

2 de Pee S, West CE, Muhilal CE, Kayadi D, Hautvast JGA. Lack of improvement in vitamin A status with increase consumption of dark-green leafy vegetables. Lancet 1995; 346 $75-81$.

3 Bulux J, Quan de Serrano J, Giuliano A, Perez R, Lopez CY, Rivera $\mathrm{C}$, et al. Plasma response of children to short-term chronic $\beta$-carotene supplementation. American Journal of Clinical Nutrition 1994; 59: 1369-75.

4 West CE, Eilander A, van Lieshout M. Consequences of revised estimates of carotenoid bioefficacy for dietary control of vitamin A deficiency in developing countries. Journal of Nutrition 2002; 132: 2920S-6S.

5 Tang G, Gu X, Hu S, Xu Q, Qin J, Dolnikowski GG, et al. Green and yellow vegetables can maintain body stores of vitamin A in Chinese children. American Journal of Clinical Nutrition 1999; 70: 1069-76.

6 de Pee S, West CE, Permaesih D, Sri Martuti, Muhilal, Hautvast JGAJ. Orange fruit is more efficient than dark green, leafy vegetables in increasing serum concentrations of retinol and $\beta$-carotene in schoolchildren in Indonesia. American Journal of Clinical Nutrition 1998; 68 1058-67.

7 Zagré NM, Delpeuch F, Traissac P, Delisle H. Red palm oil as a source of vitamin A for mothers and children: impact of a pilot project in Burkina Faso. Public Health Nutrition 2003; 6: $733-42$.

8 Drammeh BS, Marquis GS, Fonkhouser E, Bates C, Eto I, Charles B, et al. A randomized 4-months mangoes and fat trial improved vitamin A status among young Gambian children. Journal of Nutrition 2002; 132: 3693-9.

9 Ribaya-Mercado JD, Solon FS, Solon MA, Cabal-Baza MA, Perfecto CS, Tang G, et al. Bioconversion of plant carotenoids to vitamin A in Philipino school-aged children varies inversely with vitamin A status. American Journal of Clinical Nutrition 2000; 72: 455-65.

10 Takyi EK. Children's consumption of dark green leafy vegetables with added fat enhances serum retinol. Journal of Nutrition 1999; 129: 1549-54

11 Jalal F, Nesheim MC, Agus Z, Sanjur D, Habicht JP. Serum retinol concentration in children is affected by foods sources of $\beta$-carotene, fat intake and anthelmintic drug treatment. American Journal of Clinical Nutrition 1998; 68: 623-9.

12 Olson JA. Hypovitaminosis A: contemporary scientific issues. Journal of Nutrition 1994; 124: 1461S-6S.

13 Nana CP, Brouwer ID, Zagre NM, Kok FJ, Traore AS. Community assessment of availability, consumption, and cultural acceptability of food sources of (pro)vitamin A: toward the development of a dietary intervention among 
preschool children in rural Burkina Faso. Food and Nutrition Bulletin 2005; 26: 356-65.

14 Ott LR, Longnecker M, eds. An Introduction to Statistical Methods and Data Analysis, 5th ed. Pacific Grove, CA: Duxbury-Thomson Learning, 1999.

15 Nordeide MB. Table de composition d'aliments du Mali. Oslo/Mali: Institut de Nutrition Université d'Oslo/Lobo Grafisk Press, 1997.

16 Juergen E. Printed version of the new vitamin A table. Sight and Life Newsletter 2004; 1: 25-34.

17 National Academy of Sciences/Institute of Medicine. Dietary Reference Intake for Vitamin A, Vitamin K, Arsenic, Boron, Chromium, Copper, Iodine, Iron, Manganese, Molybdenum, Nickel, Silicon, Vanadium and Zinc. Washington, DC: National Academy Press, 2001.

18 Food and Agriculture Organization (FAO)/World Health Organization (WHO). Requirements for Vitamin A, Iron, Folate and Vitamin $B_{12}$. Report of a Joint FAO/WHO Expert Consultation. Food and Nutrition Series No. 23. Rome: FAO, 1988.

19 Underwood BA, Chavez M, Hankin J, Kusin JA, Omolulu A, Ranchi-Proja F, et al. Guidelines for a Development of Simplified Dietary Assessment to Identify Group At Risk for Inadequate Intake of Vitamin A. Report of the International Vitamin A Consultative Group (IVACG). Washington, DC: IVACG, 1989.

20 Sapin V, Alexandre MC, Chaib S, Bournazeau JA, Sauvant P, Borel $\mathrm{P}$, et al. Effect of vitamin A status at the end of term pregnancy on the saturation of retinol binding protein with retinol. American Journal of Clinical Nutrition 2000; 71 : 537-43.

21 World Health Organization (WHO). Indicators for Assessing $V A D$ and Their Implication for Monitoring and Evaluating Intervention Programmes. Geneva: WHO, 1996.

22 World Health Organization (WHO). Measuring Change in Nutritional Status. Geneva: WHO, 1983.

23 Kalter HD. Validation of the diagnosis of childhood mortality using maternal health interviews. International Journal of Epidemiology 1991; 20: 193-8.

24 Field A. Discovering Statistics using SPSS for Windows. London: Sage Publications Ltd, 2003.

25 de Pee S, Bloem MW, Kiess L. Evaluating food based programmes for their reduction of vitamin A deficiency and its consequences. Food and Nutrition Bulletin 2000; 21: $232-8$.
26 Gibson RS. Principles of Nutritional Assessment. New York: Oxford University Press, 2005.

27 Bates CJ. Vitamin A. Lancet 1995; 345: 31-5.

28 West CE. Meeting requirements for vitamin A. Nutrition Reviews 2000; 58: 341-5.

29 Haskell MJ, Pandey P, Graham MJ, Peerson MJ, Shrestha RK, Brown KH. Recovery from impaired dark adaptation in nightblind pregnant Nepali women who received small daily doses of vitamin A as amaranth leaves, carrots, goat liver, vitamin A-fortified rice, or retinyl palmitate. American Journal of Clinical Nutrition 2005; 81: $461-71$.

30 Munoz EC, Rosado JL, Lopez P, Furr HC, Allen LH. Iron and zinc supplementation improves indicators of vitamin A status of Mexican preschoolers. American Journal of Clinical Nutrition 2000; 71: 789-94.

31 Parvin SG, Sivakumar B. Nutritional status affects intestinal carotene cleavage activity and carotene conversion to vitamin A in rats. Journal of Nutrition 2000; 130: $373-7$.

32 Kjolhede CL, Stallings RY, Dibley MJ, Sadjimin T, Dawiesah S, Padmawati S. Serum retinol level among preschool children in Central Java: demographic and socioeconomic determinants. International Journal of Epidemiology 1995; 24: 399-403.

33 de Pee S, Dary O. Biochemical indicators of vitamin A deficiency: serum retinol and serum binding protein. Journal of Nutrition 2002; 132: 2895S-901S.

34 Allen LH. Iron supplements: scientific issues concerning efficacy and implications for research and programs. Journal of Nutrition 2002; 132: 813S-9S

35 International Vitamin A Consultative Group (IVACG). Vitamin A and Iron Interactions. IVACG Statement 1998. Washington, DC: International Life Science Institute Research Foundation, 1998.

36 O'Brien KO, Zavaleta N, Caulfield LE, Wen J, Abrams SA. Prenatal iron supplements impair zinc absorption in pregnant Peruvian women. Journal of Nutrition 2000; 130: 2251-5.

37 Whittaker P. Iron and zinc interactions in humans. American Journal of Clinical Nutrition 1998; 68: 442S-6S.

38 Wieringa FT, Dijkhuizen MA, West CE, Thurnham DI, Muhilal, van der Meer JWM. Redistribution of vitamin A after iron supplementation in Indonesian infants. American Journal of Clinical Nutrition 2003; 77: 651-7. 